\title{
Nerve conduction, tactile sensibility, and the electromyogram after suture or compression of peripheral nerve: a longitudinal study in man
}

\author{
F. B UCH TH A L A N D . K ÜH L \\ From the Laboratory of Clinical Neurophysiology and the Research Laboratories 4112 , \\ Rigshospital, Copenhagen, Denmark
}

SUMMARY In three patients sequential studies were performed of sensory and motor conduction after complete section and suture of the median nerve at the wrist and in one patient after partial section of the nerve. The sensory potential evoked by stimuli to digits III and I and recorded proximal to the suture line at the wrist appeared after a delay of three to four months, corresponding to a growth rate of $1.5-2.0 \mathrm{~mm}$ per day. From early in the course of regeneration the sensory potential was dispersed in 40 components. In the adult patient the cumulative amplitude increased for two years slowly and thereafter at a two times faster rate. Amplitude and tactile sensibility were normal after 40 months, but the sensory potential was still five times more dispersed than normal. The overall increase in the amplitude of the sensory potentials in children aged 10 and 12 years was three times faster than in the adults. In the adults and in the children the maximum sensory conduction velocity was $10-25 \%$ of normal. It then increased at $3 \%$ per month during the first two years, and thereafter 10 times slower. Forty months after suture in the adults and 13-19 months after suture in the children the conduction velocity had reached $65-75 \%$ of normal. The pattern of discrete electrical activity during voluntary effort and the $\equiv$ prolonged duration of motor unit potentials indicate persistent enlargement of the reinnervated motor units by peripheral sprouting. The sensory potential recovered five times faster after a compressive nerve lesion than after section and suture as seen in another patient with an affection of the ulnar nerve at the elbow. Normal tactile sensibility was attained 10 times faster than after section and suture. Maximum sensory and motor conduction velocity recovered within one year from $60-70 \%$ to $80-90 \%$ of normal.

Regeneration of peripheral nerve after section occurs by the outgrowth of axons from the proximal stump (Cajal, 1928; Young, 1942; Guth, 1956; Schröder, 1975). Animal studies indicate that in the early phase of regeneration the nerve fibres have small axons, thin myelin sheaths, a short internodal length, and a slow conduction velocity (Berry et al., 1944; Erlanger and Schoepfle, 1946; Sanders and Whitteridge, 1946; Cragg and Thomas, 1964; Jacobson and Guth, 1965; Gilliatt et al., 1975). The myelin sheath remains disproportionately thin and the short internodes persist even after the axons have attained near normal

Address for reprint requests: Professor F. Buchthal, Rigshospital, Section 4112, Room 1220, Blegdamsvej 9, Copenhagen 2100, Denmark. Accepted 22 November 1978 diameters (Hiscoe, 1947; Vizoso and Young, 1948; Schröder, 1972). In the cat the maximum conduction velocity of regenerating fibres increases linearly with the external diameter of the largest myelinated fibres (Berry et al., 1944), as occurs during growth of the normal nerve (Hursh, 1939).

The first study of conduction velocity in man during regeneration of motor nerve (Hodes et al., 1948) showed slowed maximum conduction velocity, prolonged motor latency, and an amplitude of the temporally dispersed muscle action potential which increased at first rapidly and thereafter more slowly, to at most $40-60 \%$ of normal 12-42 months after injury. Incomplete recovery of motor conduction was confirmed in later studies (Struppler and Huckauf, 1962; 
Ballantyne and Campbell, 1973) and agrees with experimental findings (Berry et al., 1944; Erlanger and Schoepfle, 1946; Cragg and Thomas, 1964; Jacobson and Guth, 1965). Ballantyne and Campbell (1973) recorded sensory and motor action potentials in 20 patients each examined at a different time after suture of the nerve at the wrist. They used percutaneous recording, and a sensory potential was not detected until 10 months after suture. Similarly, Tallis et al (1978) did not find a sensory potential until 18 months after a graft had been inserted. In both studies the maximum sensory and motor conduction velocity recovered to $70-85 \%$ of normal; the amplitude of the sensory potential returned to $15 \%$ of normal.

Taking advantage of the increased resolution obtained by recording from a near-nerve electrode and by averaging (Buchthal and Rosenfalck, 1966, 1971), sequential evaluations of motor and sensory conduction velocities and of the amplitude of evoked potentials from muscle and sensory nerve fibres were performed in three patients during recovery after suture of the median nerve at the wrist, and in one patient with a partial transection that was not sutured. The electrophysiological findings were related to the return of perception of light touch and pinprick. In addition, the electrical activity during voluntary effort was examined at different times during reinnervation of the abductor pollicis brevis muscle. Finally, the time course of the recovery after suture was compared with that in a patient after a transient compression of the ulnar nerve at the elbow.

\section{Methods}

The sensibility for light touch was examined by means of a soft brush, $0.75 \mathrm{~mm}$ in diameter. The force which just bent the hairs was $0.3 \mathrm{~g}$ $(0.8 \mathrm{~g} / \mathrm{mm}$ radius in stiff ness) near the normal threshold (von Frey, 1896; Head, 1920; Buchthal and Rosenfalck, 1966). Perception of superficial pain was tested with a sharp pin.

The force of the abductor pollicis brevis and the abductor digiti minimi muscles was evaluated according to a scale of 0 to 5 with subdivision of grade 4 (Medical Research Council, 1976).

The method for evoking and recording sensory potentials has already been described (Buchthal and Rosenfalck, 1966, 1971). The potentials were evoked by stimuli to the distal and the proximal phalanx of digit III, and the distal phalanx of digits $I$ and $V$. The stimulating current was $0.2 \mathrm{~ms}$ in duration and 60 to $100 \mathrm{~mA}$ (surface electrodes) or 20 to $30 \mathrm{~mA}$ (subcutaneous electrodes).

The recording electrode (bared tip $3 \mathrm{~mm}$ ) was placed near the median nerve proximal to the suture line at the wrist. To record from the ulnar nerve, recording electrodes were placed near the nerve, $50 \mathrm{~mm}$ distal and $50 \mathrm{~mm}$ proximal to the sulcus nervi ulnaris at the elbow (Payan, 1969). The distances of conduction are given in Table 1 . When the stimulus at the wrist failed to evoke a muscle action potential the electrode was placed near the nerve by using the threshold of the potential of mixed median nerve at the elbow as a gauge.

The sensory potentials were amplified (Andersen and Buchthal, 1970), digitalised, and recorded via a memory store on an ink-jet writer (Dahl and Buchthal, 1978). The criteria for identifying a summated component of the potential were that it remain similar in shape and increase with the number of responses roughly to the same extent as a calibration signal.

The stimulating current was at least 10 times

Table 1 Distances of conduction $(\mathrm{mm})$ to suture line and to recording electrode

\begin{tabular}{|c|c|c|c|c|c|}
\hline & $\begin{array}{l}B M \\
(20 y r)\end{array}$ & $\begin{array}{l}J J^{*} \\
(20 y r)\end{array}$ & $\begin{array}{l}L S \\
(12 y r)\end{array}$ & $\begin{array}{l}H J \\
(10 y r)\end{array}$ & $\begin{array}{l}\dot{E} \dot{O} H \\
(32 \text { yr })\end{array}$ \\
\hline $\begin{array}{l}\text { Digit I to suture } \\
\text { Digit I to recording electrode } \\
\text { Distal digit III to suture } \\
\text { Distal digit III to recording electrode } \\
\text { Proximal digit III to suture } \\
\text { Proximal digit III to recording electrode } \\
\text { M ABD } \text { to suture } \\
\text { M ABD } \$ \text { to recording electrode } \\
\text { Suture line to recording electrode } \\
\text { Digit V to distal to sulcus } \\
\text { Digit V to proximal to sulcus } \\
\text { Distal to proximal to sulcus }\end{array}$ & $\begin{array}{r}106 \\
128 \\
173 \\
195 \\
144 \\
166 \\
58 \\
80 \\
22\end{array}$ & $\begin{array}{l}\overline{110} \\
\overline{172} \\
\overline{145} \\
\overline{69} \\
-\end{array}$ & $\begin{array}{r}102 \\
142 \\
163 \\
183 \\
123 \\
143 \\
55 \\
75 \\
20\end{array}$ & $\begin{array}{l}102 \\
135 \\
- \\
- \\
136+\ddagger \text {, } \\
169 \ddagger \\
55 \ddagger \\
76 \\
33 \ddagger\end{array}$ & $\begin{array}{l}344 \\
452 \\
108\end{array}$ \\
\hline
\end{tabular}

* Partial lesion, not sutured.

†Digit II instead of digit III; $\ddagger$ to proximal suture line of graft.

§Abductor pollicis brevis muscle. 
the threshold of the current to evoke a muscle action potential. The muscle action potentials were recorded via a $70 \mu \mathrm{m}$ non-insulated steel wire passed through the muscle at the level of the endplate zone or, when only few motor units were active, through a coaxial needle electrode adjusted to give maximum response.

The surface temperature of the extremity was kept at $34-36^{\circ} \mathrm{C}$.

To obtain a gross expression of the number of sensory nerve fibres activated, the amplitudes of the 10 to 50 component potentials were added and denoted "cumulated amplitude." In addition to the maximum sensory conduction velocity the velocities of the last component in the main burst and of late solitary or late bursts of discharges were determined.

The electromyogram was recorded via concentric electrodes (DISA 13L51) as described by Dahl and Buchthal (1978).

\section{Results}

RECOVERY AFTER SUTURE OF THE MEDIAN NERVE AT THE WRIST

Amplitude and maximum conduction velocity of the sensory potential

In the adult (BM, Appendix, patient 1) a sensory potential was recorded for the first time four months and in the two children five and seven months after suture (Table 2). The potential evoked by stimuli to the distal phalanx of digit III consisted of 30-40 components which added to about $1.5 \mu \mathrm{V}$ (Fig. 1). In the child (HJ, Appendix, patient 3 ) in whom a graft was inserted the amplitude was much smaller. The amplitude recorded after partial section (JJ, Appendix, patient 4) was similar to that after complete section and suture when stimuli were applied to digit III whereas stimuli to digit I evoked a potential of normal size. The cumulative amplitude evoked by stimuli to the proximal phalanx was twice that evoked by stimuli to the distal phalanx. After total section and suture the eight components evoked by stimulation of digit I summed to an amplitude which was only one-tenth of that evoked by stimuli to the proximal phalanx of digit III although the distance of conduction from digit I to the wrist was shorter (Table 1).

Thus, over a distance of about $160 \mathrm{~mm}$, a sensory potential could be recorded four months after suture. As estimated from extrapolation of Fig. 2, it might have been possible to distinguish a potential from noise as early as three months after suture. After this time the cumulative amplitude in the adult increased by $0.3 \mu \mathrm{V}$ per month to the twenty-fifth month. Thereafter the increase was at a steeper rate, by $0.7 \mu \mathrm{V}$ per month, to the fortieth month, when the amplitude approached the range of normal. Forty months after suture the potential still contained five times as many components as with nerves from control subjects, the largest component being less than one-tenth of the amplitude in controls (Fig. 3).

The rate of the increase in amplitude was three times steeper in the two children (LS and HJ, Appendix, patients 2 and 3) than in the adult, the cumulative amplitude increasing by $1.0 \mu \mathrm{V}$ per month until one year after suture when it levelled off and increased only slightly to the sixteenth month; at this time it was $40-60 \%$, and the amplitude of the largest component $10 \%$ of that in control subjects (Figs. 4,5 ). The sensory potentiato was markedly more dispersed than normal. At the? thirteenth and nineteenth months the number of component potentials was twice that at five and seven months after suture.

Four to seven months after suture the fastest component of the sensory potential evoked by stimuli to the distal phalanx of digit III was conducted at $10-18 \mathrm{~m} / \mathrm{s}, 15-25 \%$ of the velocity in nerves from control subjects. The velocity from the proximal phalanx to the wrist and the velocities in the two children were about $5 \mathrm{~m} / \mathrm{s}$ faster (Table 2). The slowest components were conducted at 3-4 $\mathrm{m} / \mathrm{s}$. The maximum velocity

Table 2 Earliest sensory and motor responses recorded or evoked proximal to the suture at wrist

\begin{tabular}{|c|c|c|c|c|c|c|c|c|c|c|}
\hline \multirow{2}{*}{\multicolumn{2}{|c|}{$\begin{array}{r}\text { Patient } \\
\text { (yr) }\end{array}$}} & \multirow[b]{2}{*}{$\begin{array}{l}\text { Time after } \\
\text { suture } \\
\text { (mo) }\end{array}$} & \multicolumn{5}{|c|}{ Sensory potentials } & \multicolumn{3}{|c|}{ Motor responses } \\
\hline & & & $\begin{array}{l}\text { Conduction } \\
\text { distance } \\
(\mathrm{mm}) \dagger\end{array}$ & $\begin{array}{l}\text { Cumulative } \\
\text { amplitude } \\
(\mu V)\end{array}$ & $\begin{array}{l}\text { Peak-to-peak } \\
\text { amplitude } \\
(\mu V)\end{array}$ & $\begin{array}{l}\text { Number of } \\
\text { components }\end{array}$ & $\begin{array}{l}\text { Maximum } \\
\text { conduction } \\
(\mathrm{m} / \mathrm{s})\end{array}$ & $\begin{array}{l}\text { Conduction } \\
\text { distance } \\
(\mathrm{mm})\end{array}$ & $\begin{array}{l}\text { Peak-to-peak } \\
\text { amplitude } \\
(m V)\end{array}$ & $\begin{array}{l}\text { Latency to } \\
\text { abd+ } \\
(\mathrm{ms})\end{array}$ \\
\hline $\begin{array}{l}\text { BM } \\
\text { LS } \\
\text { HJ } \$ \\
\text { JJ*** }\end{array}$ & $\begin{array}{l}20 \\
12 \\
10 \\
20\end{array}$ & $\begin{array}{l}4 \\
7 \\
5 \\
5\end{array}$ & $\begin{array}{l}195 \\
183 \\
169 \\
172\end{array}$ & $\begin{array}{l}1.45 \\
1.85 \\
0.22 \\
1.39\end{array}$ & $\begin{array}{l}0.8 \\
0.8 \\
0.03 \\
0.08\end{array}$ & $\begin{array}{l}37 \\
27 \\
11 \\
29\end{array}$ & $\begin{array}{l}11.0 \\
18.4 \\
15.9 \\
10.0\end{array}$ & $\begin{array}{l}80 \\
75 \\
76 \\
69\end{array}$ & $\begin{array}{l}0.18 \\
1.30 \\
0.20 \\
12.5\end{array}$ & $\begin{array}{r}9.0 \\
10.6 \\
16.4 \\
3.4\end{array}$ \\
\hline
\end{tabular}

*See Appendix; †distal phalanx of digit III to wrist; †abductor pollicis brevis muscle; §graft; Idistal phalanx of digit II to wrist; ** partial lesion, no suture; T concentric electrode. 


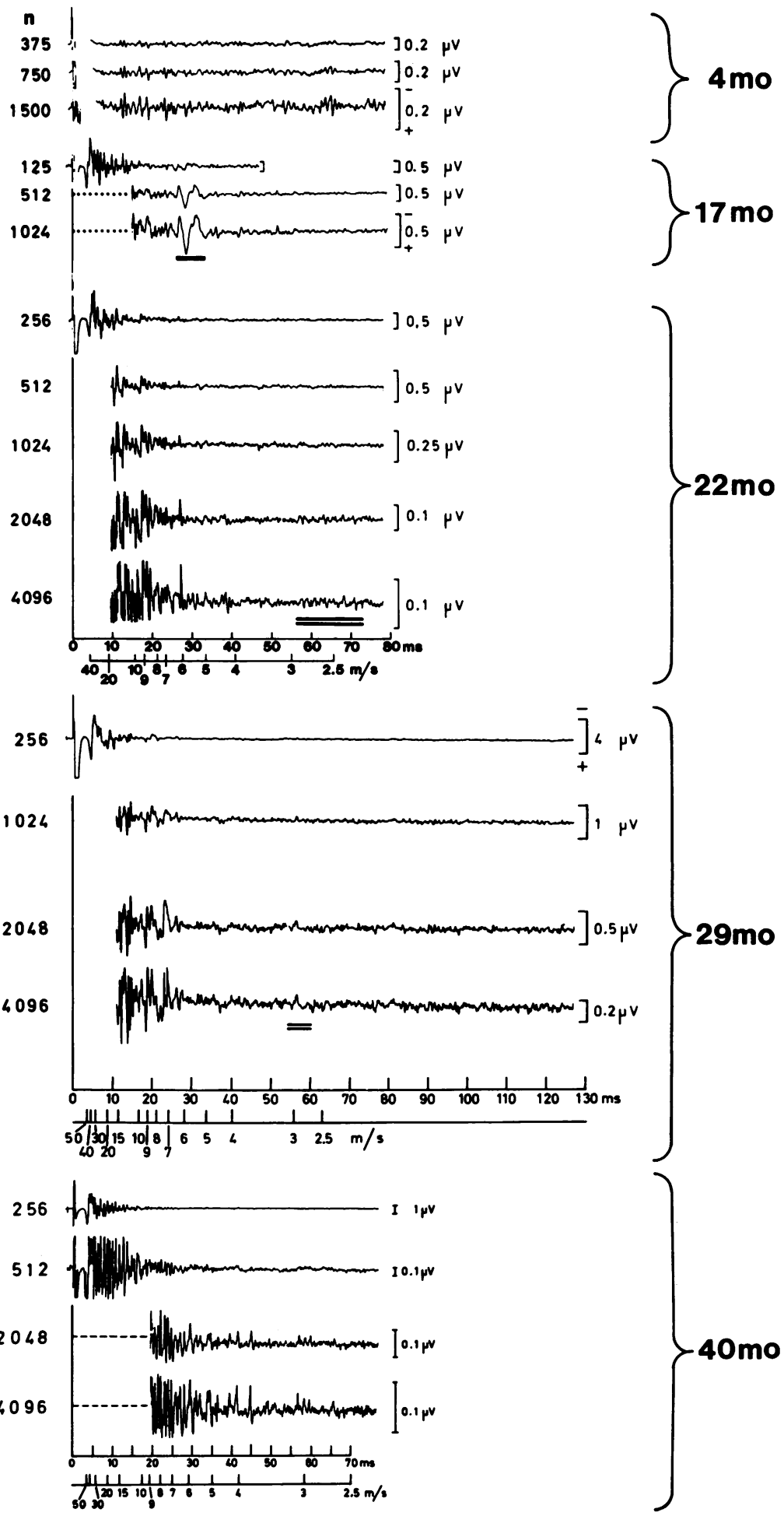

Fig. 1 Sensory potentials evoked by stimulation of the proximal phalanx of digit III and recorded from the median nerve at wrist at different times after end-to-end suture of the nerve (mo=months, $n$ denotes number of responses averaged). The horizontal bar at 17 mo marks an artefact caused by a microreflex (Buchthal et al., 1975). The twin bars at 22 and 29 mo denote trains of late components conducted at 2-3 $\mathrm{m} / \mathrm{s}$, probably generated by immature myelinated fibres. Upper scales: latencies in $\mathrm{ms}$. Lower scales: conduction velocities in $\mathrm{m} / \mathrm{s}$. Patient BM, 20 years old (cf Fig. 2 for the plot of the cumulative amplitude, Fig. 6 for the plot of the maximum conduction velocity, and Table 1 for the distances of conduction). 


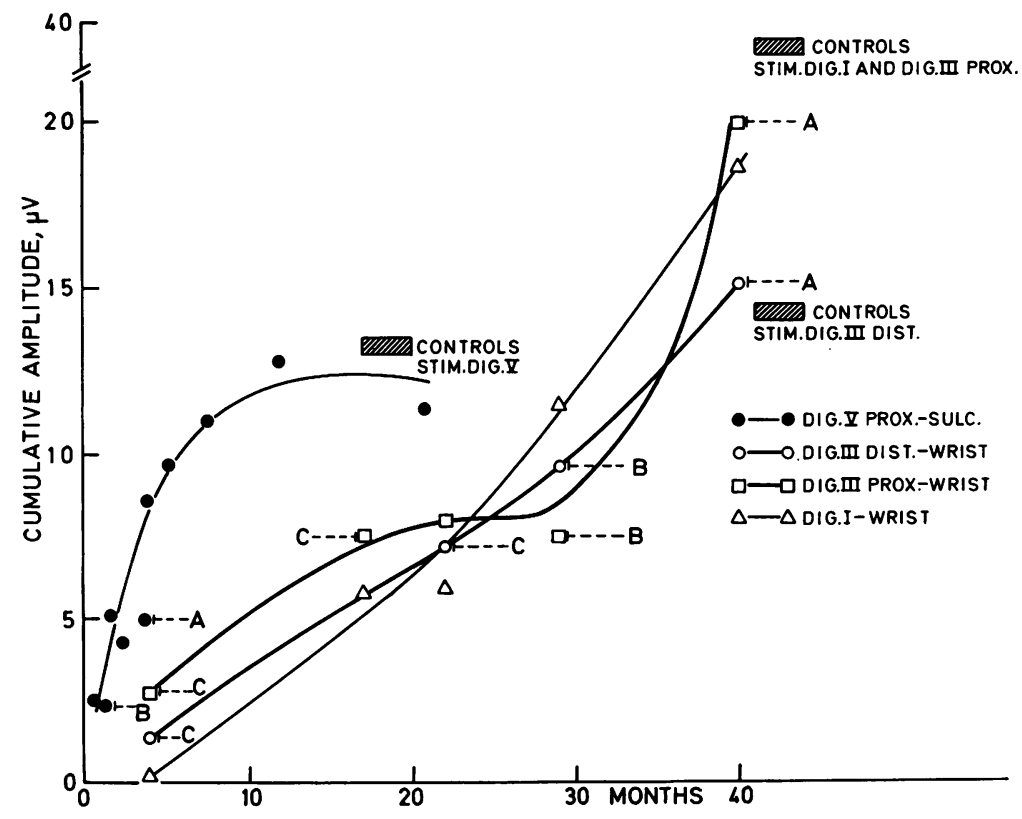

Fig. 2 Cumulative amplitude of the sensory potentials as a function of time after end-to-end suture of the median nerve at wrist (right, patient BM) and after pressure on the ulnar nerve at elbow (left, patient EÖH). Perception of tactile stimuli. A: the patient could distinguish light touch from pinprick and localise the stimulus correctly. B: the patient could distinguish light touch from pinprick but was unable to localise the stimulus correctly. C: the patient could perceive touch as an uncharacteristic stimulus, was unable to distinguish touch from pinprick and to localise the stimulus correctly. The shaded bars denote the average cumulative amplitude from control subjects matched for age (right) and from the contralateral ulnar nerve (left). The conduction distances are given in Table 1. The curves were drawn by eye. from digit I was $6 \mathrm{~m} / \mathrm{s}, 10 \%$ of that in control subjects though the distance over which regeneration had occurred was nearly $40 \mathrm{~mm}$ shorter than to the proximal phalanx of digit III (Fig. 6). Unlike the recovery of the amplitude of the sensory potential, the rate of recovery of maximum conduction velocity was initially greater than later, both in the adults and in the children (Figs. 6, 4). In the adult the velocity increased by $3 \%$ per month from four to 22 months after suture, and thereafter by $0.4 \%$ per month. At 40 months the maximum velocity was $65-75 \%$ of that in control subjects. In the nerve repaired by a graft the velocity remained low from five to eight months after suture. At the last studies, 13 and 19 months after suture when tactile sensibility was normal, the maximum velocity had recovered to 40 and $60 \%$ of normal (Fig. 4).

In the adult patient with partial division of the nerve the main component of the sensory potential was initially conducted at $10 \mathrm{~m} / \mathrm{s}(15 \%$ of normal), the velocity increasing by $10 \%$ per month to $30 \mathrm{~m} / \mathrm{s}$ (47\% of normal) eight months after the lesion, when tactile sensibility had returned to normal.
Tactile sensibility

From four months to 22 months after suture, when the cumulative amplitude had increased 3.5 times, the adult patient (BM) could perceive a tactile stimulus but could not distinguish touch from pinprick or localise the stimulus (Fig. 2). Twenty-nine months after suture, when the amplitude had begun to increase more steeply and had reached $40-60 \%$ of normal, the patient could distinguish touch from pinprick but was still unable to identify the site of the stimulus. Not until the cumulative amplitude was near normal, more than three years after suture, were tactile stimuli perceived and localised normally.

The child (LS), in whom the nerve was sutured end-to-end, could distinguish touch from pinprick but could not localise a stimulus seven months after suture-that is, 22 months earlier than the adult. The cumulative amplitude was at that time a quarter of that in the adult, when sensibility had recovered to the same extent. Recovery of tactile sensibility was delayed by two months in the child in whom a graft was inserted. Eight months after suture he was still unable to distinguish touch from pinprick and to localise the 

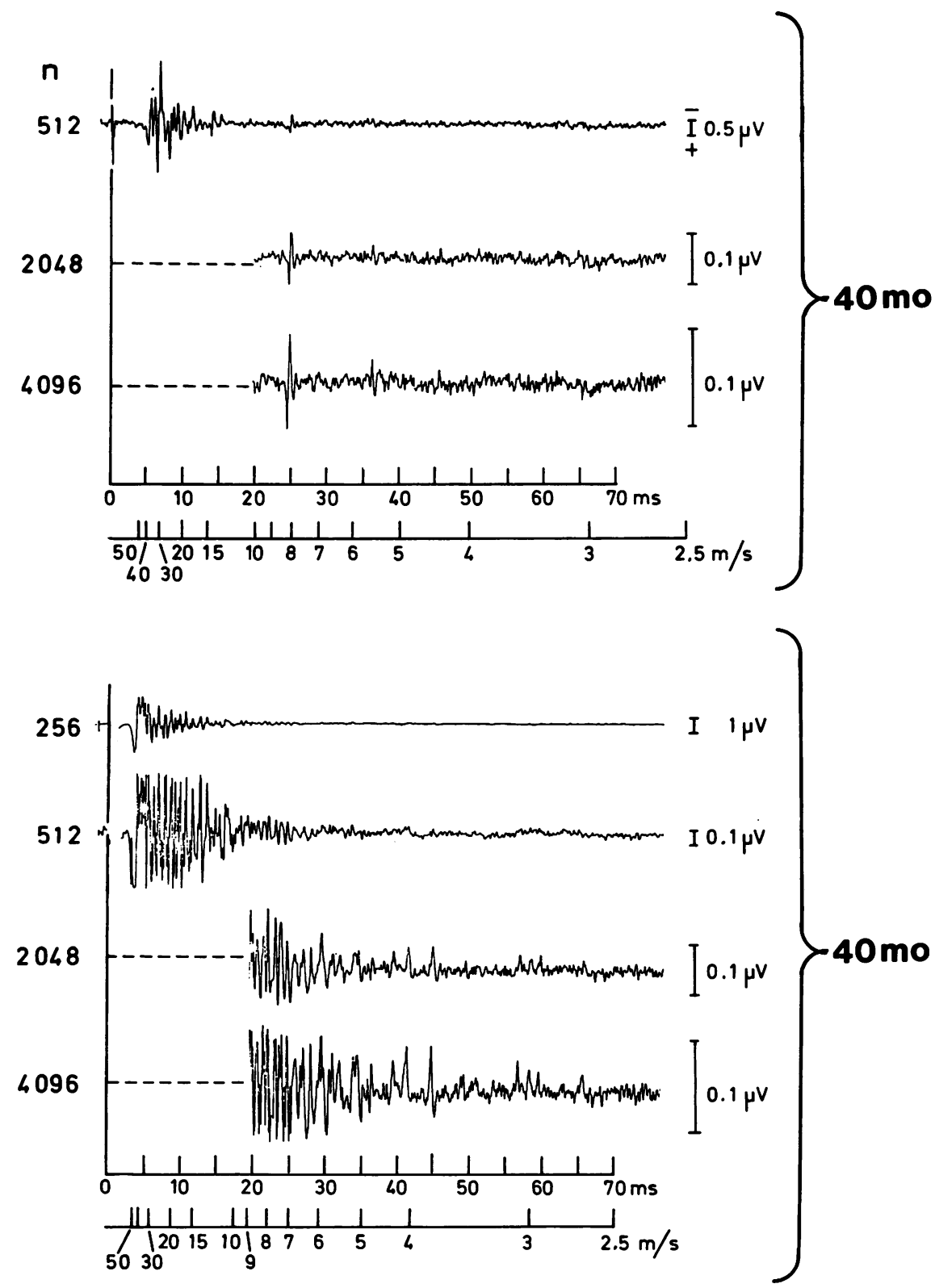

Fig. 3 Sensory potential evoked by stimulation of the distal (top) and the proximal (bottom) phalanx of digit III, recorded at wrist 40 months after end-to-end suture of the median nerve at wrist ( $n$ denotes number of responses averaged). Upper scale: latencies in ms; lower scale: conduction velocities in $\mathrm{m} / \mathrm{s}$. The conduction distances are given in Table 1. Patient BM, 20 years old. 


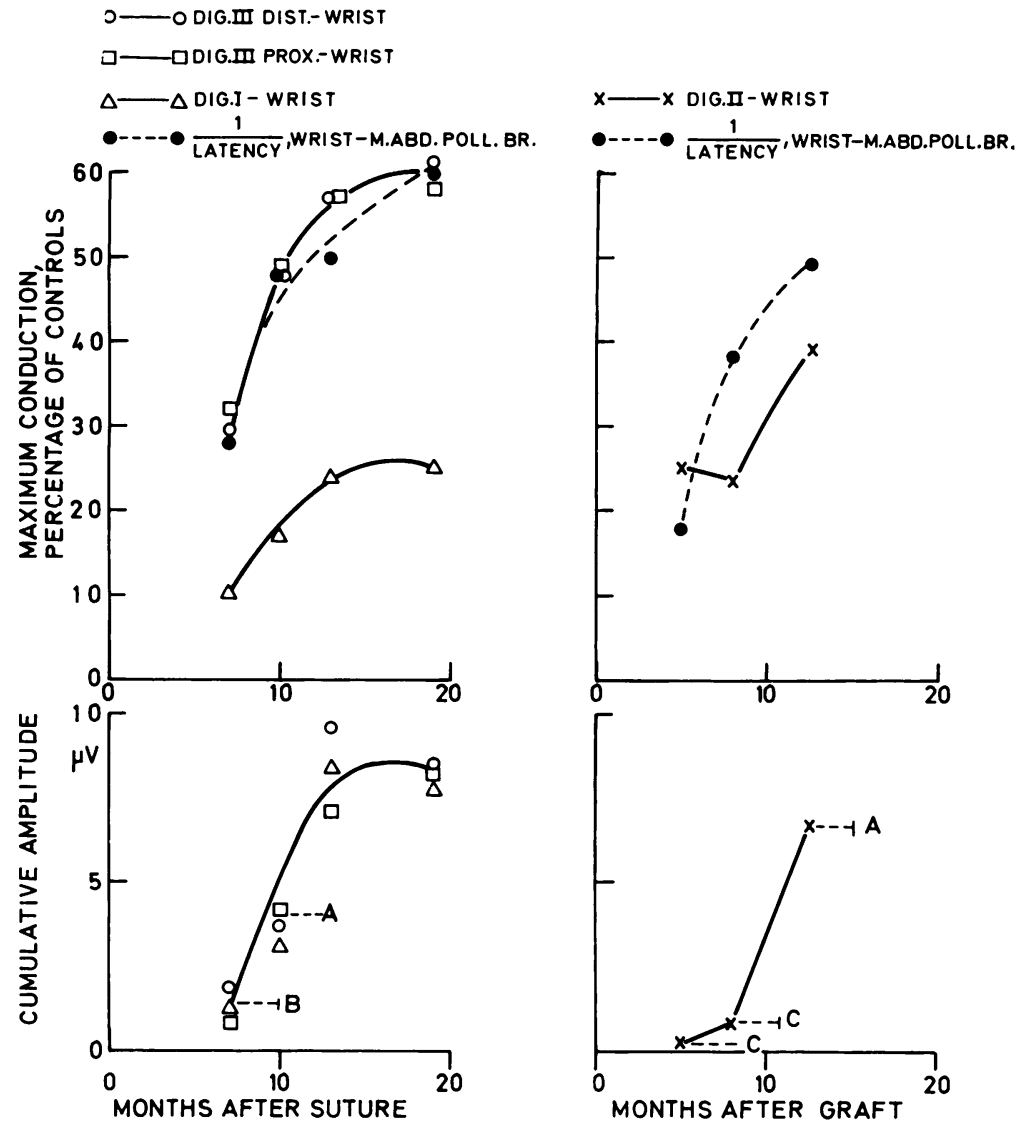

Fig. 4 Recovery of the amplitude of the sensory potential and of sensory and motor conduction after suture of the median nerve in a 12 (left, patient LS) and a 10 (right, patient $H J)$ year old child. Below: cumulative amplitude of the sensory potentials at wrist; above: maximum sensory conduction velocity and reciprocal motor latency as a function of time after end-to-end suture (left) and insertion of $a$ graft (right). In control subjects matched for age the amplitude of the sensory potential at wrist averaged $16 \mu \mathrm{V}$, when the distal phalanx, and $40 \mu V$, when the proximal phalanx of digits III or II was stimulated. For the definition of $A, B$, and $C$ see legend to Fig. 2. The conduction distances are given in Table 1.

stimulus. At 10 and 12 months after suture tactile sensation had returned to normal in both children - that is, two years earlier than in the adult (Fig. 4).

Muscle action potential and motor conduction Recorded via a wire electrode, the action potential of the abductor pollicis brevis muscle was initially $1 \%$ of the average in control subjects; the latency was three to six times prolonged (Table 2). The time course of recovery of amplitude and of latency was similar to that of the sensory potential and of sensory conduction velocity (Figs. 2, 4, 6). In the adult (BM) the amplitude reached the range of normal at 40 months when the latency was still $50 \%$ longer than normal and the force was nearly normal (graded as $4+$ ). When the abductor pollicis brevis muscle had reached normal force in the two children, the amplitude of the action potential was $25 \%$ of normal in the child whose nerve was sutured end- to-end (HS), and $15 \%$ of normal in the child in whom a graft was inserted (HJ). In both, the latency was still twice as long as in control subjects (Fig. 4).

Electrical activity during voluntary effort of the abductor pollicis brevis muscle

At the first study after suture, when there was no visible contraction, the pattern of electrical activity was discrete and of low amplitude in the adult and in the two children (Fig. 7). As the force approached normal, the pattern of activity remained discrete and its amplitude increased. The mean amplitude of randomly sampled motor unit potentials increased by $60-300 \%$ and the mean duration by $40-125 \%$, and remained so even after normal force had been attained (Fig. 8). The duration was prolonged whether or not polyphasic potentials were excluded from the calculation. The incidence of polyphasic potentials was two to three times the upper limit of normal early after 


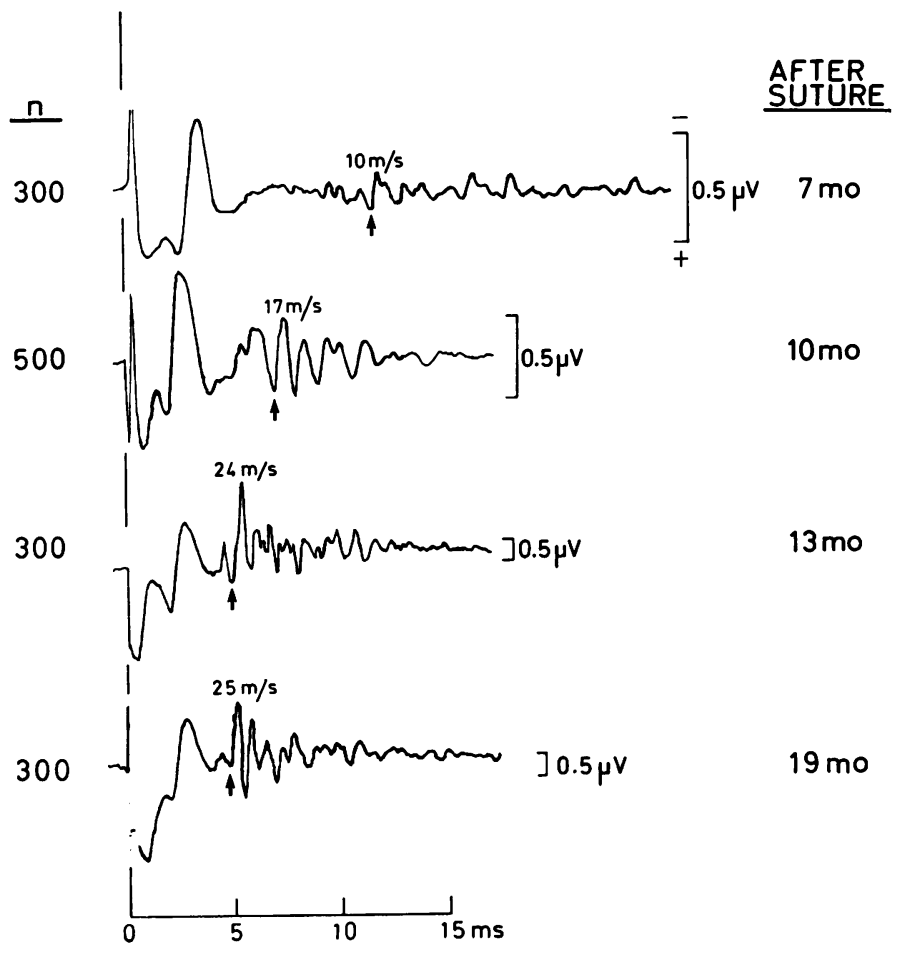

Fig. 5 Sensory potential evoked by stimulation of digit $I$ and recorded at wrist, at different times after end-to-end suture of the median nerve in a 12 year old child. The arrows denote the positive peak of the first component, identified with certainty; the figures above the traces denote the maximum conduction velocity. The initial large deflection (latency about $2 \mathrm{~ms}$ ) originated from the radial nerve. The number of responses $(n)$ that were averaged is given to the left. Patient LS, cf Fig. 4, left. The conduction distance is given in Table 1.

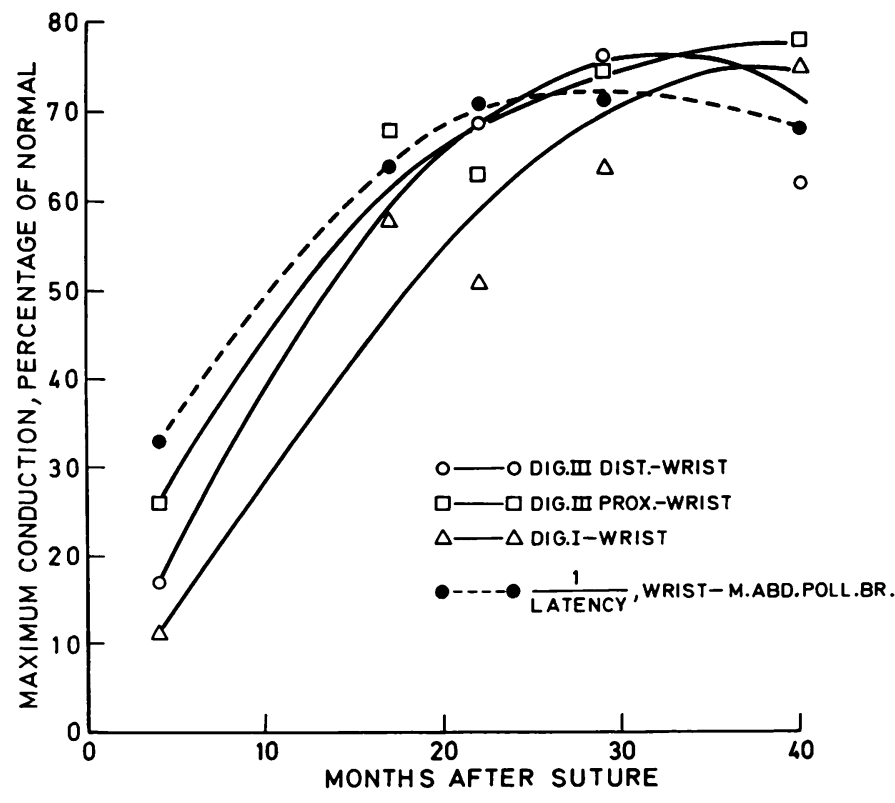

Fig. 6 Maximum sensory conduction velocity along the median nerve from digit III and digit I to wrist and reciprocal motor latency from wrist to abductor pollicis brevis muscle as a function of time after end-to-end suture. Patient BM, 20 years old. The conduction distances are given in Table 1. The curves were drawn by eye. 

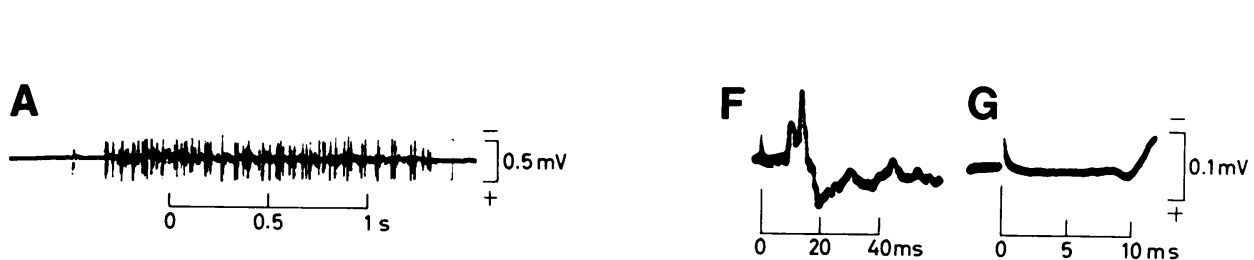

AF TER

SUTURE

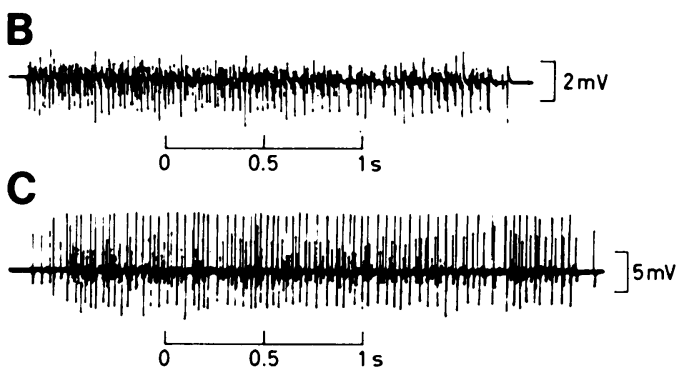

A
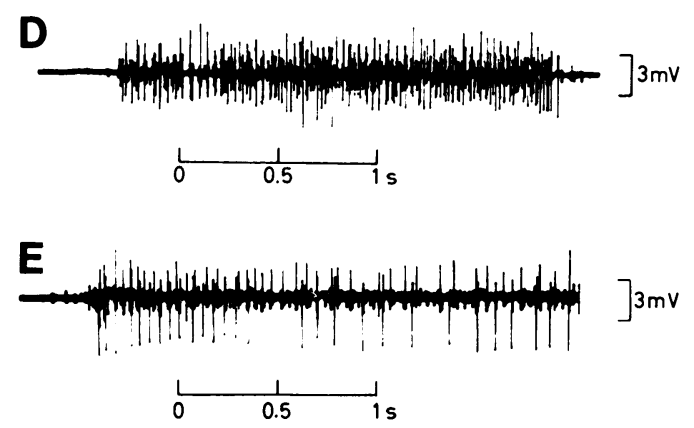

H

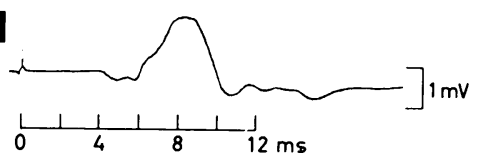

17 mo
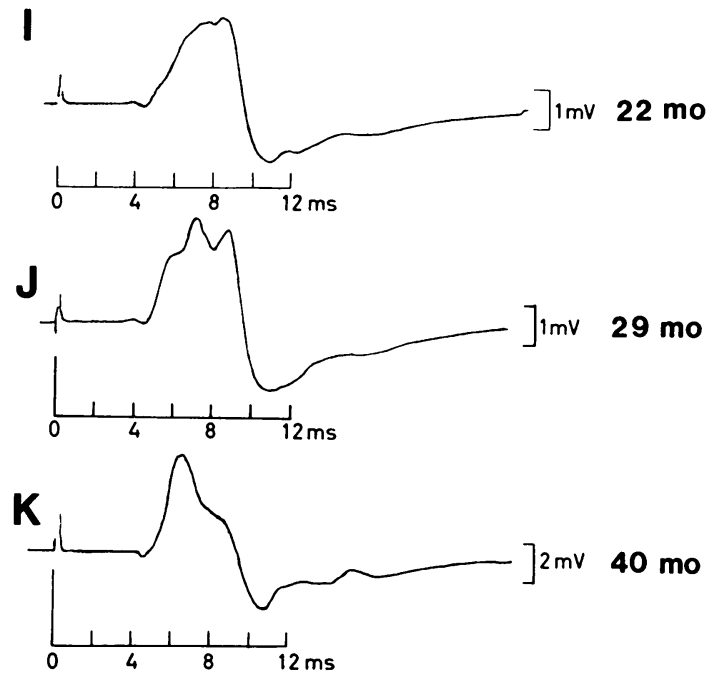

Fig. 7 Recruitment pattern during full voluntary effort of the abductor pollicis brevis muscle (A-E) and action potentials $(F-K)$ evoked by maximal stimuli to the nerve at wrist at different times after end-to-end suture of the median nerve. The first response $(F)$, evoked four months after suture, was recorded with a coaxial needle electrode, placed at the site of maximum response; $G$ was recorded with a faster sweep speed; $H-K$ were recorded with a wire electrode that traversed the cross-section of the muscle. Patient BM, 20 years old; cf the plot of the reciprocal latencies in Fig. 3 and the conduction distances in Table 1.

suture and decreased with time after suture (Fig. 8). Fibrillation potentials were recorded in four to nine sites of the muscle at all studies up to 40 months after suture.

RECOVERY AFTER COMPRESSION OF THE ULNAR NERVE AT ELBOW (APPENDIX, PATIENT EÖH)

Amplitude of the sensory potential and sensory conduction velocity

Three weeks after the episode of compression the cumulated amplitude of the sensory potential recorded proximal to the sulcus was $20 \%$ and that of the largest component $15 \%$ of the amplitude recorded from the contralateral nerve. The number of components was as in the contralateral nerve. The maximum conduction velocity from proximal to distal to the sulcus was $74 \%$ of that in the contralateral nerve. Hereafter the amplitude increased (Fig. 2), and 10 months after the episode the cumulated amplitude and the amplitude of the largest component were normal (Fig. 9). The number of components increased as well, by $25 \%$ after three months, and was twice that in the contralateral arm in the last study, 20 months after the episode (Fig. 10). Within one year after compression the maximal conduction velocity increased to $90 \%$ of normal.

\section{Tactile sensibility}

Three weeks after the episode of compression the patient complained of paraesthesia; the perception of light touch and pinprick was diminished in the 

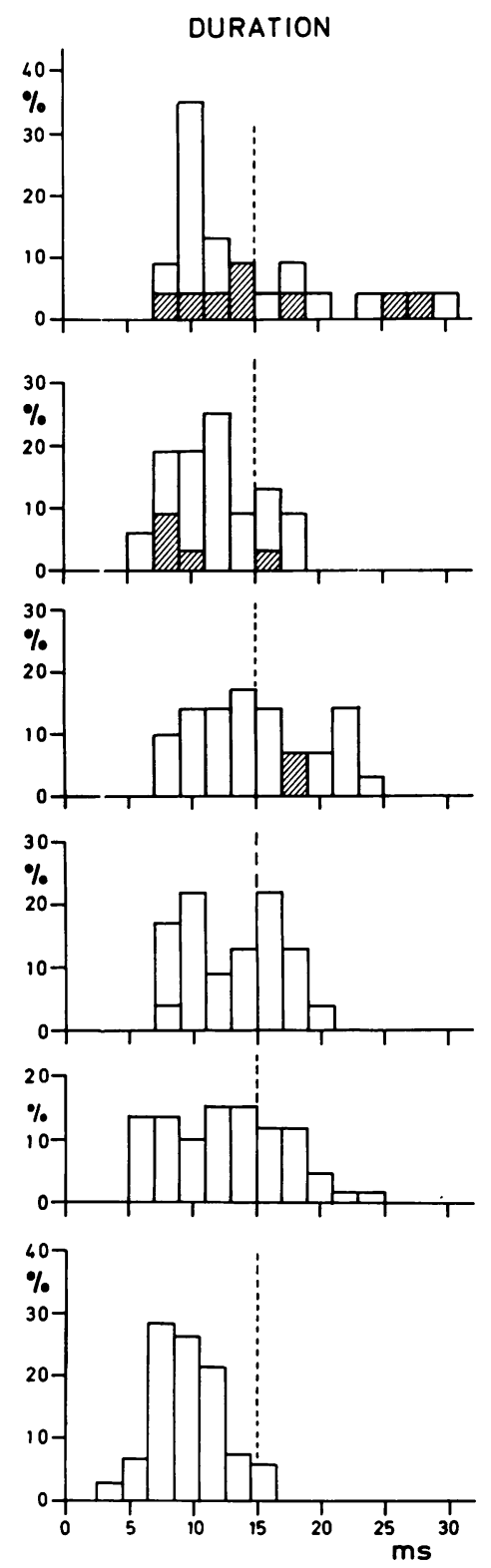

AMPLITUDE
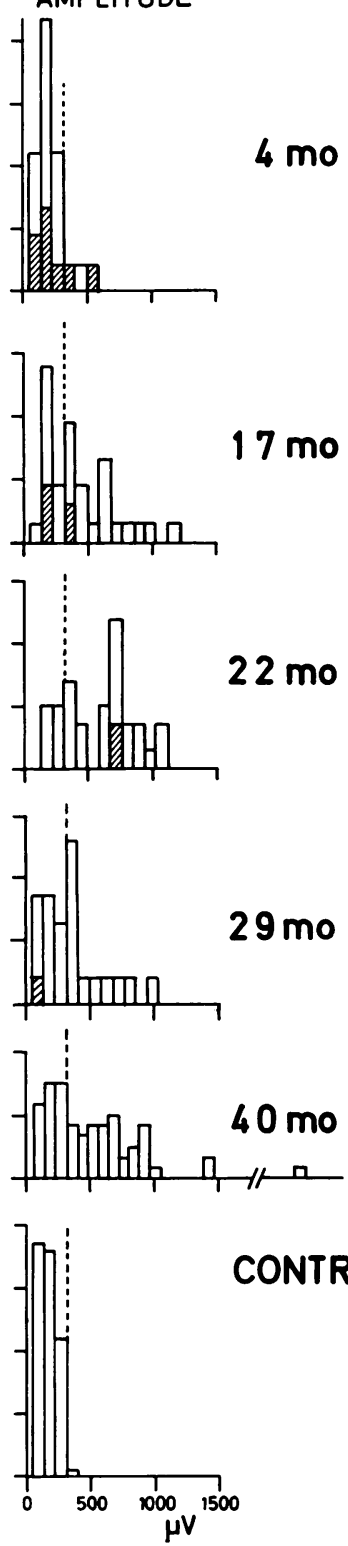

Fig. 8 Percentage distribution of the duration and the amplitude of motor unit potentials sampled in abductor pollicis brevis muscle during voluntary effort at different times after end-to-end suture of the median nerve at wrist. The striped columns indicate the incidence of polyphasic potentials. Below: 13 control subjects, matched for age. The dashed lines represent the upper $95 \%$ confidence limits. Patient BM, 20 years old. distribution of the ulnar nerve. At three months, when the cumulated amplitude was one-third of normal, the only sensory impairment was a diminished sensibility for pinprick confined to the ulnar surface of digit $\mathrm{V}$. At four months tactile sensibility had fully recovered. The amplitude was at that time two-thirds of normal.
Muscle action potential and maximum motor conduction velocity

At three weeks, stimuli proximal to the sulcus evoked a potential in the abductor digiti minimi which was $26 \%$ of that in the normal nerve and $40 \%$ of the amplitude evoked by stimuli distal to the sulcus in the impaired nerve. The maximum 


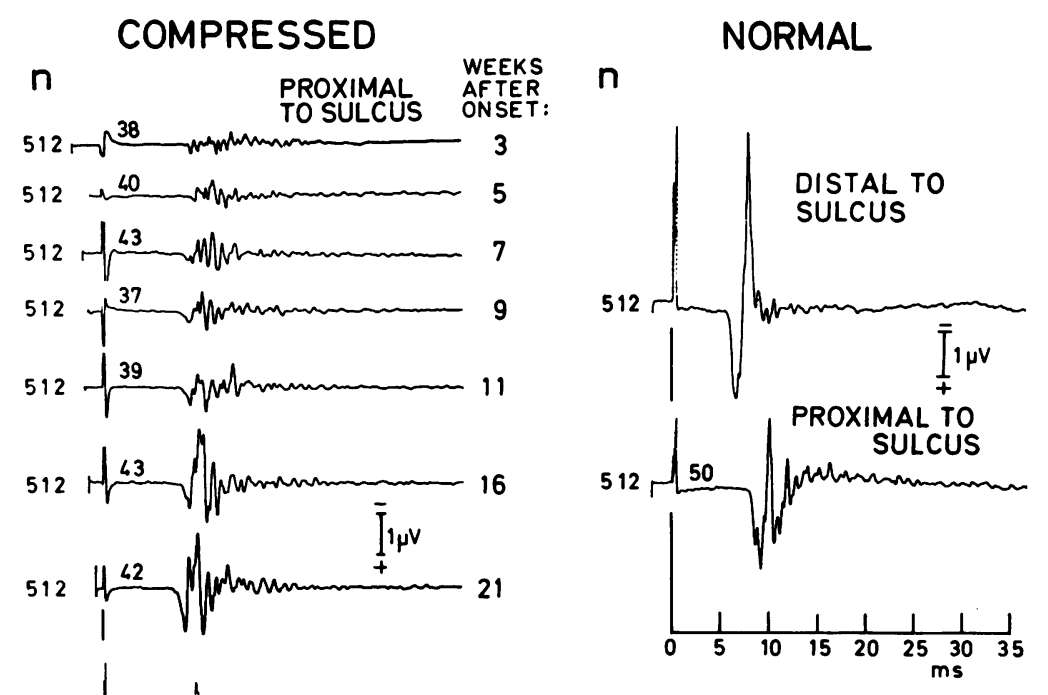

Fig. 9 Left: recovery of the sensory potential after pressure on the ulnar nerve in the sulcus. The potentials were evoked by maximal stimuli to digit $V$ and recorded at the elbow $50 \mathrm{~mm}$ proximal to the sulcus of the ulnar nerve. The figures to the right of the traces indicate weeks after the lesion. The figures above each trace give the maximum conduction velocity across the sulcus $(\mathrm{m} / \mathrm{s})$. Right: sensory potentials recorded from the contralateral ulnar nerve; the figure above the lower trace indicates the maximum conduction velocity across the sulcus. Patient EÖH, 33 years old. The conduction distances are given in Table 1.

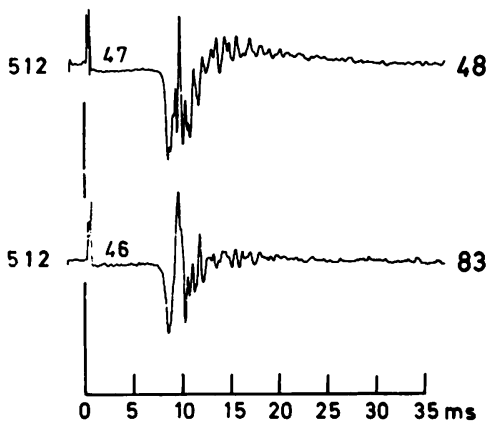

conduction velocity from proximal to distal to the sulcus was diminished to 60 or $70 \%$ of normal $(42 \mathrm{~m} / \mathrm{s}, \mathrm{m}$. abductor digiti minimi; $36 \mathrm{~m} / \mathrm{s}, \mathrm{m}$. adductor pollicis). At three months the amplitude of the muscle action potential was nearly normal, and at four months the amplitude evoked by stimuli proximal to the sulcus was the same as that evoked by stimuli distal to the sulcus. At this time the maximum conduction velocity had increased by $10 \mathrm{~m} / \mathrm{s}$ to $80 \%$ of normal. The latency from proximal to sulcus to the flexor carpi ulnaris muscle was normal throughout the study ( $3 \mathrm{~ms}$, distance of conduction $100 \mathrm{~mm}$ ).

Electrical activity during voluntary effort At three weeks the force of the abductor digiti minimi muscle was slightly diminished (graded as $4+$ ). The only electromyographic abnormality was a slight reduction in the pattern of recruitment during full effort; the amplitude was normal $(4 \mathrm{mV})$. At four months the amplitude of the recruitment pattern had increased to $6 \mathrm{mV}$, the mean duration of motor unit potentials was $26 \%$ prolonged, and polyphasic potentials and fibrillation potentials were still absent.

\section{Discussion}

Regeneration of peripheral nerve is associated with a change in amplitude, conduction velocity, and shape of the evoked sensory and motor action potentials. The change in maximum conduction velocity reflects properties of those fibres that grow fastest and that have the most rapid speed of conduction-that is, it gives information on only a small proportion of the myelinated nerve 


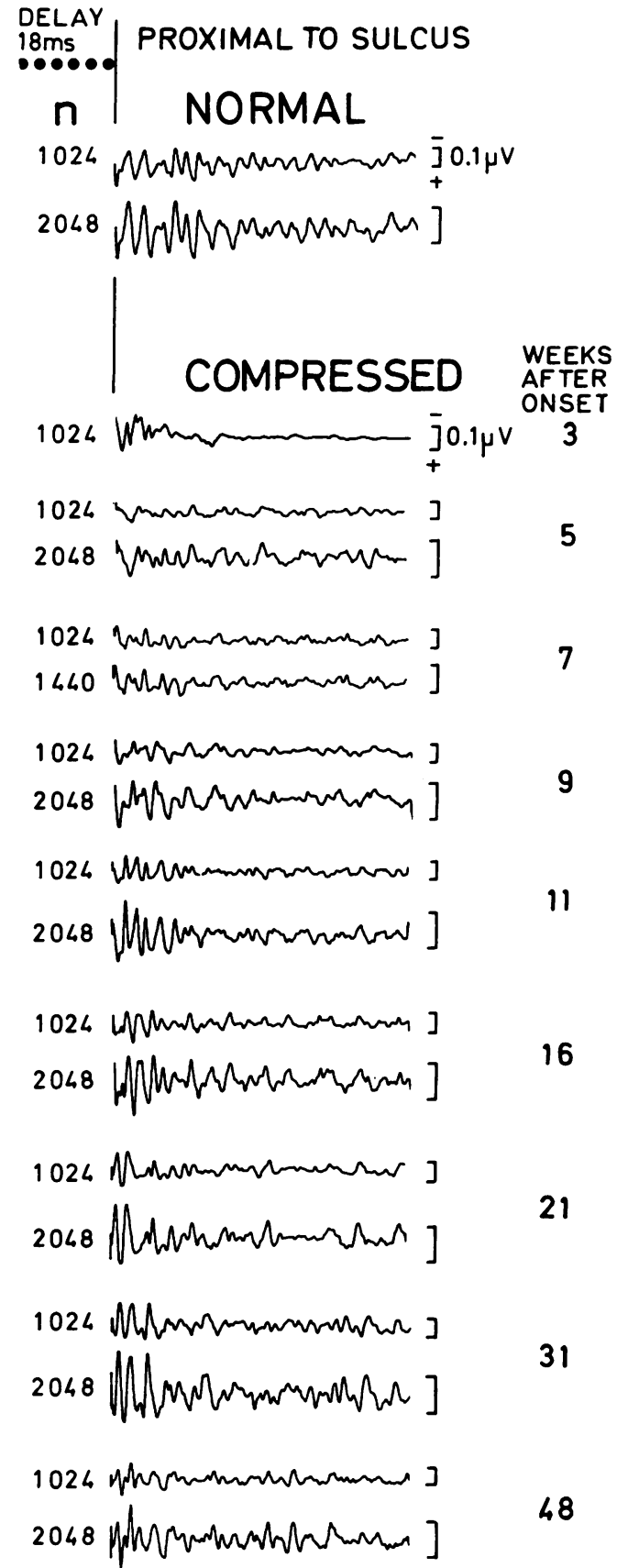

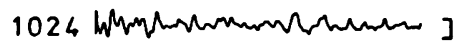

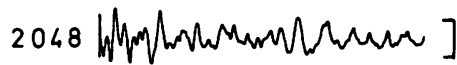

fibres. The amplitude of the sensory potential, on the other hand, in normal nerve and in nerves with purely axonal neuropathy is a measure of the number of fibres of $7 \mu \mathrm{m}$ or more in diameter that contribute to the main phase of the sensory potential. Thus, the peak-to-peak amplitude of the sensory potential of the sural nerve was grossly related to the number of large myelinated fibres (Buchthal and Behse, 1977; Behse and Buchthal, 1978). In regenerating nerve the peak-to-peak amplitude of the sensory potential is a poor gauge of the number of nerve fibres, since the sensory potential is split into many components of similar amplitude for several years after suture of the nerve. This is illustrated by the finding in Ballantyne and Campbell's (1973) and in our patients, that the peak-to-peak amplitude of the sensory potential increased little with the passage of time. The cumulative amplitude obtained by adding the component potentials seemed a better gauge of the number of nerve fibres that are activated than the peak-to-peak amplitude. We have determined the amplitude of the spike components rather than the area under the spikes. The spike duration varied less in regenerating than in normal nerve since there was less summation, and the amplitude was easier to measure than the area. The cumulative amplitude is, however, only a gross approximation as a measure of the number of fibres. Relatively more fibres contribute to a given amplitude of a slow component originating from fibres of small diameter than to the amplitude of a fast component originating from fibres of large diameter (Gasser and Erlanger, 1927). We did not correct for the relation of amplitude with the square of the diameter, since it is not known whether it is valid for incompletely myelinated fibres during regeneration. In normal nerve the amplitude of the five or six slow components recorded at the wrist is at most $2 \%$ of the amplitude of the main component. Hence, the average cumulated amplitude is about the same as the peak-to-peak amplitude.

Neither the amplitude of the sensory potential nor the maximum sensory conduction velocity was related to the improvement in two-point discrimination (Payan, 1969; Almquist and EegOlofsson, 1970; Ballantyne and Campbell, 1973) which is considered to be an accurate test to

Fig. 10 Slow components of the sensory potentials. Above: recorded from the contralateral normal ulnar nerve proximal to the sulcus. Below: recorded at different times after pressure at elbow (weeks, figures to the right). Patient EÖH, 33 years old. 
quantitate sensory loss (Moberg, 1962, Önne, 1962). The threshold to touch was related reproducibly to the amplitude and conduction velocity of the sensory potentials during recovery after local anaesthesia (Buchthal and Rosenfalck, 1966). Therefore-in the present study-we used nearthreshold stimuli for touch in addition to pinprick to assess tactile impairment.

Extrapolated from the amplitude of the sensory potential four months after the lesion, it took about 90 to 120 days before a sufficient number of myelinated fibres had regenerated to give a response that could be distinguished from noise $(>0.02 \mu \mathrm{V})$. This extrapolation seems justified because the same patient (BM) had been sutured previously, and four months after the first suture a sensory potential was absent. In nerves with near-normal conduction velocity an amplitude of the sensory potential of $0.02 \mu \mathrm{V}$ corresponds to the activation of about 10 fibres of more than $7 \mu \mathrm{m}$ in diameter. Assuming that the maximum conduction velocity of regenerating nerve decreases linearly with the diameter of the largest fibres, as shown in the cat by Berry et al. (1944), and, assuming that the amplitude of the action potential in regenerated fibres is related to the cross-sectional area of the nerve fibres as in normal nerve (Gasser and Erlanger, 1927), it would take about 40 fibres to produce a response of $0.02 \mu \mathrm{V}$ that is conducted at $10-20 \mathrm{~m} / \mathrm{s}$. A delay of 90 to 120 days for the first response to be measured corresponds to a rate of recovery of 2.0 to $1.5 \mathrm{~mm}$ per day assuming that the distance of regeneration extends $20 \mathrm{~mm}$ into the proximal stump (170+ $20 \mathrm{~mm}$ ). This is in agreement with previous estimates (the advance of Tinel's sign and of returning sensibility, Seddon et al., 1943; Bowden and Sholl, 1954). With percutaneous recording it took 2.5-4 times longer before the first sensory potential could be distinguished from noise (Ballantyne and Campbell, 1973; Tallis et al., 1978).

At the time when a sensory potential was just recorded some degree of tactile perception had been re-established. When light touch or pinprick was applied to digit III the patient perceived a stimulus but was unable to identify its type or site of application. That tactile stimuli were perceived at all, although the number of excitable large myelinated fibres was presumably about $1 \%$ of normal, is consistent with the perception of a stimulus applied to a single cutaneous afferent nerve fibre in man (Hensel and Boman, 1960) and with the return of the perception of touch during recovery from local anaesthesia when the amplitude of the sensory potential is still markedly diminished (Buchthal and Rosenfalck, 1966).
When a sensory potential could be recorded, the motor latency from just proximal to the site of suture to the abductor pollicis brevis muscle was prolonged more than three times and the amplitude of the muscle action potential was less than $1 \%$ of the average in control subjects. Electromyography during voluntary effort showed evidence of regeneration as well, although clinical testing did not reveal activity in the muscle. The marked increase in mean duration of motor unit potentials and in the incidence of polyphasic potentials reflects reinnervation.

Until two years after suture the cumulated amplitude of the sensory potential increased slowly by $2 \%$ per month reflecting the appearance of additional fibres and the increase in diameter of regenerating fibres (Young, 1942). During this time the perception of tactile stimuli remained markedly impaired. At 28 months after suture the cumulated amplitude had recovered to half that of normal nerve and tactile perception improved such that touch could be distinguished from pinprick but the site of the stimulus could still not be recognised. From two to three years after suture the cumulated amplitude increased more rapidly (3\% per month) and approached normal. The peak-to-peak amplitude was, however, only $6-7 \%$ of normal, consistent with the persisting marked temporal dispersion of the sensory potential. There were $30-60$ components compared to 5-7 witho normal nerve. The patient was now able to localise also the site of the stimulus.

The slow increase in the amplitude of the evoked muscle action potential with time after suture reflects an incomplete synchronisation of the component potentials as well; at 40 months the amplitude was only half of that in control subjects, although the force was nearly normal.

The maximum rate of sensory and motor conduction increased at first rapidly, by $3 \%$ per month, and thereafter more slowly, by $0.3 \%$ per month, similar to findings in cat (Berry et al., 1944) and rabbit nerve (Sanders and Whitteridge, 1946). As the velocity of the fastest fibres increased, the slower components also moved to faster velocities, and new slow components appeared that were absent in previous recordings. Even 40 months after suture recovery of the conduction velocity of the fastest fibres was incomplete, to $80 \%$ of normal, in agreement with most previous findings in animals (Berry et al., 1944; Cragg and Thomas, 1964) and in man (Ballantyne and Campbell, 1973). The distal motor latency was at that time 1.5 times normal. The improvement in tactile perception occurred while there was little change in maximum sensory conduction 
velocity and confirms findings in patients investigated five years or longer after the suture (Almquist and Eeg-Olofsson, 1970).

Denervated muscle fibres are reinnervated either by regeneration or by sprouting of intramuscular nerve branches - that is, by the incorporation of denervated muscle fibres into motor units that already have become reinnervated. Which of the two processes prevails depends on the speed at which regeneration proceeds. In rat soleus muscle, if regeneration occurs early during the sprouting, the synapses established by the sprouts are eliminated within a few weeks and the enlarged motor units again become smaller. When regeneration is delayed the motor units innervated by sprouts retain their increased size (Thompson and Jansen, 1977; Thompson, 1978). The fact that full voluntary effort in the reinnervated muscles of the patients was associated with a pattern of discrete discharges, even after the force of the muscle had become nearly normal, indicates that the nerve fibres, regenerated earliest, had sprouted and that the enlargement of the motor units persists. Because of the larger distance of regeneration, reinnervation is delayed in man and peripheral sprouting is of greater importance than in the rat. The fivefold increase in amplitude of the discharges during the first year of follow-up and the prolonged mean duration of motor unit potentials are consistent with the assumption that the increase in force is due to an enlargement of the initially reinnervated motor units by peripheral sprouting. The high incidence of polyphasic potentials which decreased with the passage of time is presumably the result of slow conduction along immature sprouts, the temporal dispersion decreasing as the sprouts grow in diameter and become fully myelinated. Possibly the transient lesser increase in the duration of motor unit potentials observed 10-17 months after suture reflects a period of hyperinnervation (Guth, 1962).

Hodes et al. (1948) observed that partially transected nerve, which did not require suture, often recovered faster than completely transected and sutured nerve. In our patient with partial transection of the median nerve the peak-to-peak amplitude increased three times faster with time after the lesion than did the amplitude of the sensory potential during regeneration after complete section and suture. The increase in cumulative amplitude was, however, similar after partial and after complete transection because after partial transection the temporal dispersion decreased while it remained constant or increased after complete transection.
In the child in whom end-to-end suture was performed the delay until the first sensory and muscle action potential appeared was similar to that in the adults (growth rate $2 \mathrm{~mm}$ per day); in the child in whom a nerve transplant was inserted and the regenerating fibres had to traverse the barrier of a second suture, the delay was twice as long. After the initial delay, the cumulative amplitude and the maximum sensory conduction velocity increased three times faster than in the adult nerve. Tactile function was normalised much earlier than in the adult. This confirms the findings of Önne (1962) and of Almquist and Eeg-Olofsson (1970). The distal motor latency was initially increased six to seven times; it recovered at the same fast rate as the maximum sensory conduction velocity. Normal muscle power was attained twice as fast as in adults.

The five times faster rate of recovery in amplitude of the sensory potential after transient local compression than after transection and suture reflects the faster repair of demyelination than of fibre loss by regeneration. Nevertheless, it took about one year after compression until the cumulative amplitude reached normal and recovery was still proceeding, since there were twice as many slow components in the sensory potential of the previously compressed nerve than of the normal nerve. Whether some of the slow components originate from regeneration of fibres that were destroyed by the compression cannot be decided. They were, however, conducted at a faster velocity than the slowest components, one to three years after transection and suture. The maximum sensory conduction velocity across the region of compression was initially diminished by $25 \%$; it remained at this level for eight months and seemed a poor indicator of recovery. Tactile perception had fully recovered four months after the compression when the cumulative and the peak-topeak amplitude of the sensory potential had reached two-thirds of normal. The much earlier recovery of tactile perception after compression than after transection is probably due to the absence of neuronal branching and of misalignment of regenerating fibres.

We are indebted to the late Mrs Ulla Scheel and to Mr K. Dahl for their able help during the study, and to Dr S. Horowitz, Professor A. Rosenfalck, and $\mathrm{Dr} \mathrm{W}$. Trojaborg for helpful criticism of the manuscript. The work was supported by grants from the Muscular Dystrophy Associations of America, New York, and the Michaelsen Foundation, Copenhagen. 


\section{Appendix}

PATIENTS WITH INJURY OF THE MEDIAN NERVE AT THE WRIST

Case 1 A 20 year old female accountant (BM) incurred, in a traffic accident, a fracture of the radius, the ulna, and the triquetrum at the wrist with luxation of the joint. End-to-end sutures of the ulnar and median nerves were performed a few hours after the accident. Two weeks later a neuroma was removed from the ulnar nerve. Inspection of the median nerve did not show a neuroma. At four months neither touch nor pinprick was perceived in the area of the median nerve, the force of the abductor pollicis brevis muscle was graded as 0 , motor unit potentials were absent during voluntary effort, and there were fibrillation potentials and positive sharp waves in five sites. At five months the median nerve was re-explored and found to be buried in fibrous tissue. A neuroma was removed and a new perineurial end-to-end suture was performed. Three months later the pain had subsided. The patient noticed when the hand and the proximal phalanx of the median-innervated digits were touched but could describe neither the site nor the type of the stimulus. The force in the abductor pollicis brevis muscle was graded as 0 . The time course of recovery was followed from the time of the second suture until 40 months later.

Case 2 A 12 year old girl (LS) fell over a tent pole and cut her wrist. Two days later the wrist was explored, the median nerve was found to be severed, and a perineurial end-to-end suture was performed. Her recovery was followed over 19 months. At six weeks she could perceive a stimulus in the palm of the hand, but not on the digits innervated by the median nerve. There were paraesthesias but no pain. The force of the abductor pollicis brevis muscle was graded as 0 . At six months she still complained of paraesthesia in digits II and III. She perceived a stimulus on the proximal phalanx of digits II and III but was unable to distinguish touch and pinprick and to localise the stimulus. The force of the abductor pollicis brevis muscle was graded as 0 to 1 . Ten and 13 months after suture, touch of the digits elicited pricking paraesthesia lasting for several seconds; there was no pain. The force of the abductor pollicis brevis muscle was graded as 1. At 19 months pinprick elicited pricking and tingling, less than one second in duration. The force of the abductor pollicis brevis muscle was nearly normal (graded as $4+$ ).

Case 3 A 10 year old boy ( $\mathrm{HJ}$ ) fell on a glass door and injured his right wrist. Tactile stimuli were not perceived in the distribution of the median nerve although the nerve showed continuity one day after the injury. Seven months after the injury tactile sensibility was absent, and touch of the scar elicited pain irradiating to the digits innervated by the median nerve. A neuroma was removed and a $40 \mathrm{~mm}$ long graft from the sural nerve was inserted by epineurial sutures. The proximal suture line was $150 \mathrm{~mm}$ from the tip of digit II. The pain subsided. His recovery was followed for 13 months after the suture.
Case 4 A 19 year old assistant nurse (JJ) incurred a $10 \mathrm{~mm}$ deep incision at the wrist when she fell against a window. The tendon of the palmaris longus muscle was sutured. The median nerve was not exposed since tactile sensibility of the hand and movement of the thumb seemed unimpaired. One week after the lesion the sensibility for touch was diminished in the distribution of the median nerve; pinprick was normally perceived. There was neither pain nor paraesthesia. Five months after the lesion the sensibility for touch and pinprick was diminished in the distribution of the median nerve, and tactile stimuli elicited pricking paraesthesia in digits I to IV but no pain. The force and the electromyogram of the abductor pollicis brevis muscle were normal. Eight months after the lesion the paraesthesia had subsided. The perception of touch and pinprick was diminished in the distal phalanges of digits II, III, and IV (radial side). Electrophysiological studies were obtained five and eight months after the injury.

\section{PATIENT WITH COMPRESSION OF THE ULNAR NERVE AT} THE ELBOW

A 33 year old carpenter (EÖH) was seen three weeks after he had "slept" on his right elbow in a drunken stupor. He was not an habituated alcoholic. He complained of paraesthesia in digits IV and V. The perception of touch and pinprick was diminished in digit $\mathrm{V}$ and on the ulnar side of digit IV. The force of the abductor digiti minimi muscle slightly reduced (graded as $4+$ ). Five weeks after the episode of compression the paraesthesia in digits IV and $\mathrm{V}$ and the diminution in sensibility of touch and pinprick were less marked The force of the abductor digiti minimi muscle was stille slightly reduced. At seven weeks the paraesthesia was confined to digit $\mathrm{V}$ and the decrease in sensibility for touch and pinprick to the ulnar surface of digit $\mathrm{V}$. At nine and 11 weeks there was slight paraesthesia in digit $\mathrm{V}$, and the diminution in tactile sensibility on the ulnar surface of digit $\mathrm{V}$ was less than at seven weeks. The force of the abductor digiti minimi muscle was normal. At four months the paraesthesia had subsided, and the only abnormality was a slight diminution in the perception of pinprick on the ulnar surface of the distal phalanx of digit V. At five, seven, 12, and 21 months the tactile sensibility and the force of the ulnar-innervated muscles were normal.

\section{References}

Almquist, E., and Eeg-Olofsson, O. (1970). Sensory nerve conduction velocity and two-point discrimination in sutured nerves. Journal of Bone and Joint Surgery, 52-A, 791-796.

Andersen, V. O., and Buchthal, F. (1970). Low noise alternating current amplifier and compensator to reduce stimulus artefact. Medical and Biological Engineering, 8, 501-508.

Ballantyne, J. P., and Campbell, M. J. (1973). Electrophysiological study after surgical repair of sectioned human peripheral nerves. Journal of Neurology, Neurosurgery, and Psychiatry, 36, 797-805. 
Behse, F., and Buchthal, F. (1978). Sensory action potentials and biopsy of the sural nerve in neuropathy. Brain, 101, 473-493.

Berry, C. M., Grunfest, H., and Hinsey, J. C. (1944). The electrical activity of regenerating nerves in the cat. Journal of Neurophysiology, 7, 103-115.

Bowden, R. E. M., and Sholl, D. A. (1954). In Peripheral Nerve Injuries, Medical Research Council, Special Report Series, no. 282, pp. 16-24. Edited by Her Majesty's Stationery Office: London.

Buchthal, F., and Rosenfalck, A. (1966). Evoked action potentials and conduction velocity in human sensory nerves. Brain Research, 3, 1-122.

Buchthal, F., and Rosenfalck, A. (1971). Sensory potentials in polyneuropathy. Brain, 94, 241-262.

Buchthal, F., and Behse, F. (1977). Peroneal muscular atrophy (PMA) and related disorders. I. Clinical manifestations as related to biopsy findings, nerve, conduction and electromyography. Brain, $\mathbf{1 0 0}$, 41-66.

Buchthal, F., Rosenfalck, A., and Behse, F. (1975). Sensory potentials of normal and diseased nerves. In Peripheral Neuropathy, chapter 21, pp. 442-464. Edited by P. O. Dyck, P. K. Thomas and E. H. Lambert. W. B. Saunders: Philadelphia, London, Toronto.

Cajal, Ramon y, S. (1928). Degeneration and Regeneration in the Nervous System, pp. 1-769. Humphrey Milford: London.

Cragg, B. G., and Thomas, P. K. (1964). The conduction velocity of regenerated peripheral nerve fibres. Journal of Physiology (London), 171, 164-175.

Dahl, K., and Buchthal, F. (1978). Digital memory recorder in electromyography and nerve conduction studies. Electroencephalography and Clinical Neurophysiology, 45, 538-544.

Erlanger, J., and Schoepfle, G. M. (1946). A study of nerve degeneration and regeneration. American Journal of Physiology, 147, 550-581.

Frey, M. von (1896). Untersuchungen über die Sinnesfunktionen der menschlichen Haut. Abhandlungen der Königlich Sächsischen Gesellschaft der Wissenschaften, Mathematisch-Physikalische Klasse, 3, 218-238.

Gasser, H. S., and Erlanger, J. (1927). The role played by the constituent fibres of a nerve trunk in determining the form of its action potential wave. American Journal of Physiology, 80, 522547.

Gilliatt, R. W., Fowler, T. J., and Rudge, P. (1975). Peripheral neuropathy in baboons. In Advances in Neurology, volume 10, pp. 253-272. Edited by B. S. Meldrum and C. D. Marsden. Raven Press: New York.

Guth, L. (1956). Regeneration in the peripheral nervous system. Physiological Reviews, 36, 441-478.

Head, H. (1920). Studies in Neurology, pp. 1-262. Oxford Medical Publications: London.

Hensel, H., and Boman, K. K. A. (1950). Afferent impulses in cutaneous sensory nerves in human subjects. Journal of Neurophysiology, 23, 564-578.
Hiscoe, H. B. (1947). Distribution of nodes and incisures in normal and regenerated nerve fibres. Anatomical Record, 99, 447-475.

Hodes, R., Larrabee, M. C., and German, W. (1948). The human electromyogram in response to nerve stimulation and the conduction velocity of motor axons. Archives of Neurology and Psychiatry (Chicago), 60, 340-365.

Hursh, J. B. (1939). Conduction velocity and diameter of nerve fibres. American Journal of Physiology, 127, 131-139.

Jacobson, S., and Guth, L. (1965). An electrophysiological study of the early stages of peripheral nerve regeneration. Experimental Neurology, 11, 48-60.

Medical Research Council (1976). Aids to the Examination of the Peripheral Nervous System, pp. 1-62. Her Majesty's Stationery Office: London.

Moberg, E. (1962). Criticism and study of methods for examining sensibility in the hand. Neurology (Minneapolis), 12, 8-19.

Önne, L. (1962). Recovery of sensibility and sudomotor activity in the hand after suture. Acta Chirurgica Scandinavica, Supplement 300, 1-69.

Payan, J. (1969). Electrophysiological localization of ulnar nerve lesions. Journal of Neurology, Neurosurgery, and Psychiatry, 32, 208-220.

Sanders, F. K., and Whitteridge, D. (1946). Conduction velocity and myelin thickness in regenerating nerve fibres. Journal of Physiology (London), 105, 152-174.

Schröder, J. M. (1972). Altered ratio between axon diameter and myelin sheath thickness in regenerated nerve fibres. Brain Research, 45, 49-65.

Schröder, J. M. (1975). Degeneration and regeneration of myelinated nerve fibres in experimental neuropathies. In Peripheral Neuropathy, chapter 16, pp. 337-362. Edited by P. J. Dyck, P. K. Thomas, and E. H. Lambert. W. B. Saunders: Philadelphia, London, Toronto.

Seddon, H. J., Medawar, P. B., and Smith, H. (1943). Rate of regeneration of peripheral nerves in man. Journal of Physiology (London), 102, 191-215.

Struppler, A., and Huckauf, H. (1962). Propagation velocity in regenerated motor nerve fibres. Electroencephalography and Clinical Neurophysiology, Supplement, 22, 58-60.

Tallis, R., Staniforth, P., and Fisher, T. R. (1978). Neurophysiological studies of autogenous sural nerve grafts. Journal of Neurology, Neurosurgery, and Psychiatry, 41, 677-683.

Thompson, W. (1978). Reinnervation of partially denervated rat soleus muscle. Acta Physiologica Scandinavica, 103, 81-91.

Thompson, W., and Jansen, J. K. S. (1977). The extent of sprouting of remaining motor units in partly denervated immature and mature rat soleus muscle. Neuroscience, 2, 523-535.

Vizoso, A. D., and Young, J. Z. (1948). Internodal length and fibre diameter in developing and regenerating nerves. Journal of Anatomy, 82, 110-134.

Young, J. Z. (1942). The functional repair of nervous tissue. Physiological Reviews, 22, 318-374. 